\title{
Enhanced Public Health Surveillance for the Sixth Worldwide Uchinanchu Festival Conducted by the Okinawa Prefectural Government, Japan
}

\author{
Munesada Yamakawa1, Miyuki Yamauchi', Minoru Nidaira1, Tomoyuki Azuma², \\ Tadashi Nakasone ${ }^{2}$, Fumie Ando², Takahiro Hayamizu², Saki Kinjo², Yuuki Nakamura ${ }^{3 *}$ \\ ${ }^{1}$ Regional Public Health Division, Department of Public Health and Medical Care, Okinawa Prefectural Government, Okinawa, \\ Japan \\ ${ }^{2}$ Naha City Public Health Center, Okinawa, Japan \\ ${ }^{3}$ Graduate School of Pharmacy, Nihon University, Chiba, Japan \\ Email: yamakamn@pref.okinawa.lg.jp, yamaucmy@pref.okinawa.lg.jp, nidairam@pref.okinawa.lg.jp, \\ 68217TOMO@city.naha.lg.jp,68225TADA@city.naha.lg.jp,66869fumi@city.naha.lg.jp, \\ 67717TAKA@city.naha.lg.jp,66494SAKI@city.naha.lg.jp, *contact@syndromic-surveillance.com
}

How to cite this paper: Yamakawa, M., Yamauchi, M., Nidaira, M., Azuma, T., Nakasone, T., Ando, F., Hayamizu, T., Kinjo, S. and Nakamura, Y. (2017) Enhanced Public Health Surveillance for the Sixth Worldwide Uchinanchu Festival Conducted by the Okinawa Prefectural Government, Japan. Journal of Biosciences and Medicines, 5, 106-115.

https://doi.org/10.4236/jbm.2017.59010

Received: August 24, 2017

Accepted: September 18, 2017

Published: September 21, 2017

Copyright (c) 2017 by authors and Scientific Research Publishing Inc. This work is licensed under the Creative Commons Attribution International License (CC BY 4.0).

http://creativecommons.org/licenses/by/4.0/

\section{(c) (i) Open Access}

\begin{abstract}
Objective: The Okinawa prefectural government conducted enhanced surveillance for the Sixth Worldwide Uchinanchu Festival, with participation of more than 5300 visitors from abroad, many of whom were Okinawan or of Okinawan descent, for early detection of Zika virus disease and other potential public health threat outbreaks. Method: Enhanced surveillance conducted from 12 October through 13 November involved four surveillance systems, (Nursery) School Absenteeism Surveillance system ((N)SASSy), Prescription Surveillance (PS), and Official Syndromic Surveillance (OSS), each of them operates routinely, in addition to case-based and sentinel surveillance under the Infectious Diseases Control Law as Official National Surveillance of Infectious Diseases (ONSID). This enhanced surveillance was conducted for analysis and evaluation, with intensive information sharing among concerned parties. Result: We performed the enhanced surveillance for 33 days from 12 October through 13 November. Information from enhanced surveillance was analyzed and evaluated, and eventually summarized as a daily report. There has been one rubella case at an elementary school in Okinawa City on 20 October and a measles case at an elementary school in Uruma City on 2 November. Those two cases were registered into (N)SASSy on a timely basis. The public health center investigated them quickly, and the measles case was denied later because symptoms did not satisfy with case definition. Discussion:
\end{abstract}


We regard enhanced surveillance as useful to confirm events that might demand a public health response. Moreover, the related including public health centers or medical institutions confirmed the situation as valuable for the administrative structure. However, because almost all (nursery) schools or pharmacies are closed during successive holidays, outbreaks that occur on such days cannot be recognized on a timely basis. More sensitive surveillance for such days, with better preparations for ambulance transfer and at emergency departments in hospitals remains as a challenge for future work.

\section{Keywords}

Enhanced Surveillance, Syndromic Surveillance, Mass Gathering, School Absenteeism, Prescription

\section{Introduction}

Okinawa hosted the Sixth Worldwide Uchinanchu Festival during 26 - 30 October, 2016. It was attended by more than 5300 visitors from abroad, mainly Okinawan or of Okinawan descent. Many South American visitors were expected to participate, because Zika virus disease was epidemic in that area at that time [1] [2]. Zika virus disease outbreak during the festival was regarded as a possible phenomenon.

In general, politically high-profile events such as the G7 or APEC summit meeting or important visiting dignitaries, or mass gathering events such as the Olympic and Paralympic games or the FIFA World Cup present heightened risks of infectious disease because unusually large numbers of visitors enter the country and bioterrorism attacks become more probable. Regarding earlier detection of outbreaks for such an event, public health agents sometimes conduct enhanced surveillance using syndromic surveillance in addition to traditional surveillance based on physicians' diagnoses [3]-[14]. In Japan, enhanced surveillance had been conducted in the past for the Kyushu Okinawa Group of Eight Summit (G8 summit) 2000 [6] [7], the FIFA World Cup 2002 competition [8] [9], the Hokkaido Toyako G8 summit meeting 2008 [10], President Obama's visit to Japan in 2009 [11], the Yokohama Asia-Pacific Economic Cooperation (APEC) 2010, the Nagoya Tenth meeting of the Conference of the Parties (COP10) 2010 [12], the Fourth Japan-China-South Korea Trilateral Summit in 2011 [13], the Sports Festival in Tokyo 2013 [14] and Ise-Shima G7 summit meeting 2016.

The Okinawa prefectural government conducted enhanced surveillance for the Sixth Worldwide Uchinanchu Festival for earlier detection of Zika virus disease and other potential public health threat outbreaks. This paper summarizes results and offers some advices for enhanced surveillance to be conducted in the near future, including the 2020 Tokyo Olympic and Paralympic games of 2020. 


\section{Materials and Methods}

Enhanced surveillance conducted during 12 October through 13 November involved four surveillance systems, (Nursery) School Absenteeism Surveillance system ((N)SASSy), Prescription Surveillance (PS), Official Syndromic Surveillance (OSS) Official National Surveillance of Infectious Diseases (ONSID), and Notification of Measles in Okinawa. All of which operate routinely, in addition to case-based and sentinel surveillance covered under the Infectious Diseases Control Law. This enhanced surveillance was operated as analysis and evaluation with intensive information sharing among the related institutions in Okinawa Prefecture.

\section{1. (N)SASSy}

(N)SASSy has been active since January 2009 after undergoing a thorough fundamental study. This unique surveillance is made available in Japan because the parents of students are required by the schools to report the reasons for their child's absence from school activities. Guardians are required by the schools to report their child's symptoms before a diagnosis is made by a doctor. After being diagnosed by a doctor, they are required to report their diagnosis to schools as the reason for their child's absence. By reporting the diagnosed certain type of disease such as influenza or varicella from parents, the school can order the student to be "suspended" from school activities to prevent disease transmission inside class, specific grade, or school. Days during the suspended period were not counted against the total number of days required to advance to the next school grade. (N)SASSy is an internet-based system through which a school representative with access to the system makes a daily record of the reported information about infection-related absenteeism and suspensions. Okinawa prefecture joined (N)SASSy since 2016.

We apply EARS [15] to detect aberrations in the number of suspensions because of infection, or absence in each symptom in a city, town, or village at three classifications. Low aberration was defined as a day's number of patients being higher than the average of the prior seven days by three standard deviations, which is original definition of $\mathrm{C} 1$ in EARS. Moderate aberration was defined as four standard deviations higher. High aberration was defined as five standard deviations higher.

\subsection{PS}

After thorough and fundamental assessment, Prescription Surveillance (PS) has been conducted nationally including Okinawa prefecture since January 2009. Fifty six pharmacies in Okinawa prefecture (about $12 \%$ of all pharmacies in Okinawa prefecture) were participating in PS. By this surveillance, the only data collected are the numbers of prescriptions issued, classified into classification of drugs by efficacy. Therefore, the collected data include no personal information. Data for the number of prescriptions are extracted automatically and are ana- 
lyzed daily through the receipt computer, the Application Service Provider (ASP). The surveillance monitors drugs categorized as "relief of fever and pain," "drugs for common colds," "antibiotics," "anti-influenza virus drugs" (excluding amantadine), and "anti-Varicella-Zoster virus drugs," with the last two categories further sub-classified by age: "younger than 15," "16 - 64," and "older than 65 years old." As surveillance for potential bioterrorism using smallpox, we monitored changes in prescriptions of acyclovir to adults, without increase in the population of children or elderly people.

Aberrations in PS are defined at each participating pharmacy using historical analysis by which the targeted drug prescription was regressed on the dummy variables for the epidemiological week number, the day of the week, holiday, the day after holidays and a linear time trend. We recognized a higher aberration if today's number of prescriptions of the drug exceeded the prediction from the estimation using all data up to the prior day by five standard deviations of the prediction. Similarly, moderate aberration was found for four standard deviations; low aberration was found for three standard deviations. Aberrations at the community level were defined by integration of the aberrations at pharmacies in the community. We assigned scores to high aberration as 1 , to moderate aberration as 0.5 , to low aberration as 0.25 , and to no aberration as 0 . Then we calculated the average score over participating pharmacies in the community. If the average was higher than 0.3 , then we defined high aberration in the community, moderate as 0.2 , and low as 0.1 .

\subsection{OSS}

OSS based on the Infectious Diseases Control Law started on April 1, 2008. When a physician at a designated medical facility (sentinel clinic or hospital) sees a patient meeting the reporting criteria, the facility must immediately make a report to the public health center via internet or fax. The report criteria are the following: 1) fever higher than $38^{\circ} \mathrm{C}$ and respiratory symptoms (except for external injury or organic cause) (respiratory symptoms refers to critical cases that must be admitted to a hospital), or 2) fever and rash or blistering skin disease (except for symptoms that are clearly from diseases classified in categories II-IV, under the Law). Throughout the duration of the enhanced surveillance, fever and rash or blistering skin disease (the second criteria) was especially monitored closely for surveillance of bioterrorism using smallpox. In this enhanced surveillance, information about OSS was reported from 24 sentinel medical institutions for OSS, 11 cooperation medical institutions for OSS, and the Naha Quarantine Station.

\subsection{ONSID}

ONSID is also based on the Infectious Diseases Control Law like OSS. All, or sentinel medical institutions must report patients diagnosed by a doctor, and who are compatible with reporting criteria. 


\subsection{Notification of Measles in Okinawa}

Although measles is classified as category $\mathrm{V}$ of the Law and the diagnosed doctor is obligated to report it to a public health center within seven days, Okinawa Prefectural Office of the Public Health uniquely asked them to report it immediately.

\subsection{Evaluation and Information Sharing}

We evaluate the surveillance, integrate it as a daily report and share information on all days including weekends. We asked those concerned as a public health center to collect more detailed information and responses, when we found some aberration, if necessary.

\section{Results}

We conducted enhanced surveillance for 33 days from 12 October through 13 November. Information from the enhanced surveillance was analyzed and evaluated, and summarized as the daily report. Daily reports were published on the Okinawa Prefecture homepage. The responses, mainly by the public health centers, are presented in Table 1.

During these periods, by (N)SASSy, 22 high level, 22 moderate level, and 27 low level aberrations were detected. In addition, for "class/school closing," shut downs caused by influenza were reported in Naha city, Uruma city, Okinawa city, Tomigusuku city, Haebaru town, Nishihara town, Yomitan village, and Yonabaru city (Figure 1).

PS detected 2 high level, 22 moderate level, and 163 low level aberrations. The two high-level aberrations were all for "Neuraminidase inhibitors" (Figure 2).

OSS and Notification of Measles in Okinawa issued two and three reports, respectively (Figure 3). The public health center collected detailed information from medical institutions.

A rubella case was found at an elementary school in Okinawa City on 20 October and a measles case in an elementary school in Uruma City on 2 November. Those two cases were registered into (N)SASSy in a timely manner. The public health center was able to investigate them quickly.

\section{Discussion}

During enhanced surveillance, each surveillance system was able to detect aberrations, as described in Results. However, more patients tend to visit a doctor's office on Monday or the first non-holiday of the work week because medical institutions are closed on Sunday or holidays. Therefore, (N)SASSy or PS sometimes records disproportionately more aberrations on such days. Moreover, situations of outbreaks occurring in those days cannot be recognized on a timely basis because almost all (nursery) schools or pharmacies are closed during the successive holidays. More sensitive surveillance is necessary for those days, with preparations for ambulance transfer [14] and emergency department in hospitals [16]. Coordination of such measures remains as a challenge for future study. 
Table 1. Detected events and response.

\begin{tabular}{|c|c|c|c|c|}
\hline Date & Type of Surveillance & Location & Event & Response \\
\hline 11 Oct. & (N)SASSy & $\begin{array}{l}\text { Tomigusuku } \\
\text { City }\end{array}$ & Class closure in a high school & $\begin{array}{l}\text { We published some caution related to influenza on comment } \\
\text { in }(\mathrm{N}) \text { SASSy. }\end{array}$ \\
\hline 12 Oct. & ONSID & Naha City & $\begin{array}{l}\text { Number of influenza } \\
\text { patients per sentinel in Naha } \\
\text { was } 11.17\end{array}$ & $\begin{array}{l}\text { Naha City Public Health Center published an Influenza } \\
\text { Warning. }\end{array}$ \\
\hline 14 Oct. & $\begin{array}{c}\text { Notification of } \\
\text { Measles in Okinawa }\end{array}$ & Okinawa City & $\begin{array}{l}\text { Medical institution reported } \\
\text { a suspected case }\end{array}$ & $\begin{array}{l}\text { The Chubu Public Health Center collected the detail situation } \\
\text { and PCR test was examined at the public laboratory. On 17, it } \\
\text { was negative in PCR. }\end{array}$ \\
\hline 17 Oct. & OSS & Naha City & $\begin{array}{l}\text { Medical institution reported } \\
\text { a patient with rash and fever }\end{array}$ & $\begin{array}{l}\text { Naha City Public Health Center collected situation details; } \\
\text { influenza virus, Adenovirus, RS virus and hemolytic } \\
\text { Streptococcus were negative by rapid test. }\end{array}$ \\
\hline 19 Oct. & $\begin{array}{c}\text { Notification of } \\
\text { Measles in Okinawa }\end{array}$ & Uruma City & $\begin{array}{l}\text { Medical institution reported } \\
\text { a suspected case }\end{array}$ & $\begin{array}{l}\text { The Chubu Public Health Center collected the detail situation } \\
\text { and PCR test was examined at the Public Laboratory. On 20, it } \\
\text { was negative in PCR. }\end{array}$ \\
\hline 20 Oct. & (N)SASSy & Okinawa City & $\begin{array}{l}\text { Suspended because rubella } \\
\text { was registered }\end{array}$ & $\begin{array}{l}\text { The Public Health Center collected situation details. The } \\
\text { medical institution ordered tests for the commercial } \\
\text { laboratory; the school encouraged their students without } \\
\text { vaccination to immunization. On } 24 \text {, it was IgM negative. }\end{array}$ \\
\hline 21 Oct. & $\begin{array}{c}\text { Notification of } \\
\text { Measles in Okinawa }\end{array}$ & Naha City & $\begin{array}{l}\text { Medical institution reported } \\
\text { a suspected case }\end{array}$ & $\begin{array}{l}\text { The Naha City Public Health Center collected the detail } \\
\text { situation and PCR test was examined at the public laboratory. } \\
\text { On 22, it was negative in PCR. }\end{array}$ \\
\hline 26 Oct. & ONSID & $\begin{array}{l}\text { Whole of } \\
\text { Okinawa } \\
\text { Prefecture }\end{array}$ & $\begin{array}{l}\text { Number of influenza } \\
\text { patients per sentinel } \\
\text { throughout Okinawa } \\
\text { prefecture was } 10.25\end{array}$ & Influenza Warning was issued for all of Okinawa prefecture \\
\hline $\begin{array}{l}26-27 \\
\text { Oct. }\end{array}$ & (N)SASSy & $\begin{array}{l}\text { Kitadaito } \\
\text { Village }\end{array}$ & $\begin{array}{l}\text { In all, } 14 \text { kids were registered } \\
\text { as having pertussis. }\end{array}$ & $\begin{array}{l}\text { The Nanbu Public Health Center collected information in } \\
\text { cooperation with clinics. The clinic also prevented } \\
\text { transmission in cooperation with the large hospital. }\end{array}$ \\
\hline 31 Oct. & Oss & Naha City & $\begin{array}{l}\text { Medical institution reported } \\
\text { a patient with rash and fever }\end{array}$ & $\begin{array}{l}\text { Naha City Public Health Center collected situation details and } \\
\text { did not order PCR test for measles based on observations for } \\
\text { the patient. }\end{array}$ \\
\hline 2 Nov. & $(\mathrm{N})$ SASSy & Uruma City & Measles case was registered & $\begin{array}{l}\text { The child did not visit a doctor. Therefore, the Chubu Public } \\
\text { Health Center recommended that parents visit a doctor. The } \\
\text { doctor denied a measles infection. }\end{array}$ \\
\hline
\end{tabular}

Notes: (N)SASSy is (Nursery) School Absenteeism Surveillance System, OSS is Official Syndromic Surveillance, and ONSID is Official National Surveillance of Infectious Diseases.

Enhanced surveillance is useful to confirm conditions under which no public health response is necessary. Moreover, confirmation of such situations by related public health centers and medical institutions is expected to be valuable for the administrative structure. In addition, concerned people can be aware of the situation and be reminded of standard precautions. Other countermeasures are expected to be more effective if an infectious disease is spreading in a community.

As described above, there was one rubella case and one measles case. The measles case was denied later because symptoms did not satisfy with case definition however, (N)SASSy encouraged rapid investigation by the public health 


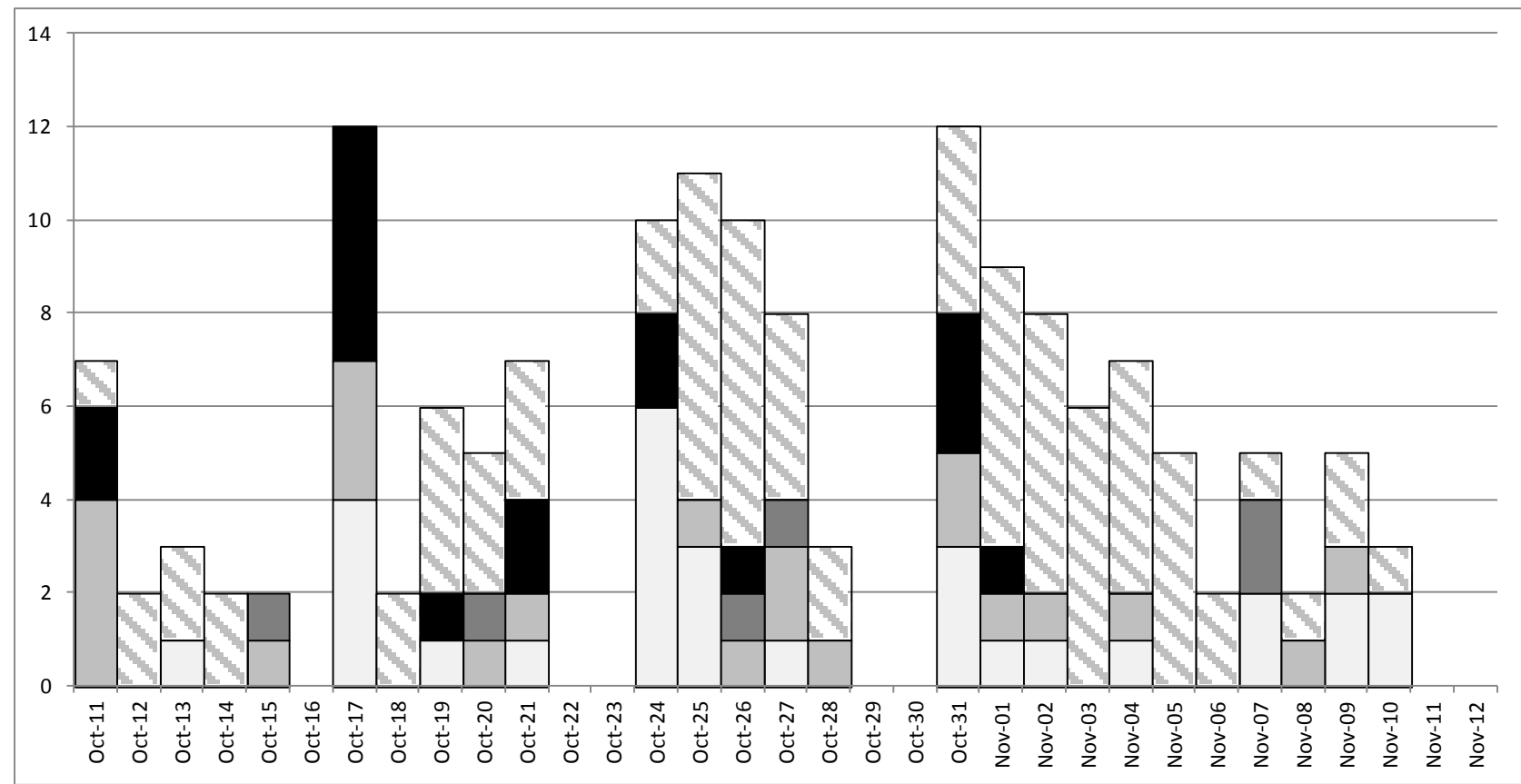

Figure 1. Detected Aberrations by (Nursery) School Absenteeism Surveillance System. Note: The lowest toned bar shows the number of low aberrations, the second toned bar shows moderate aberrations, the third toned bar shows high aberrations attributable to diseases other than influenza, the black bar shows high aberration because of influenza, and the shaded bar shows class closures. Other infectious diseases were acute hemorrhagic conjunctivitis in the Yaeyama public health center's jurisdiction on 15 October, rubella in the Chubu public health center's jurisdiction on 20 October, pertussis in the Nanbu public health center's jurisdiction on 25 - 26 October, mycoplasma pneumonia in the Chubu public health center's jurisdiction on 17 November, and mumps in the Nanbu public health center's jurisdiction on 17 November.

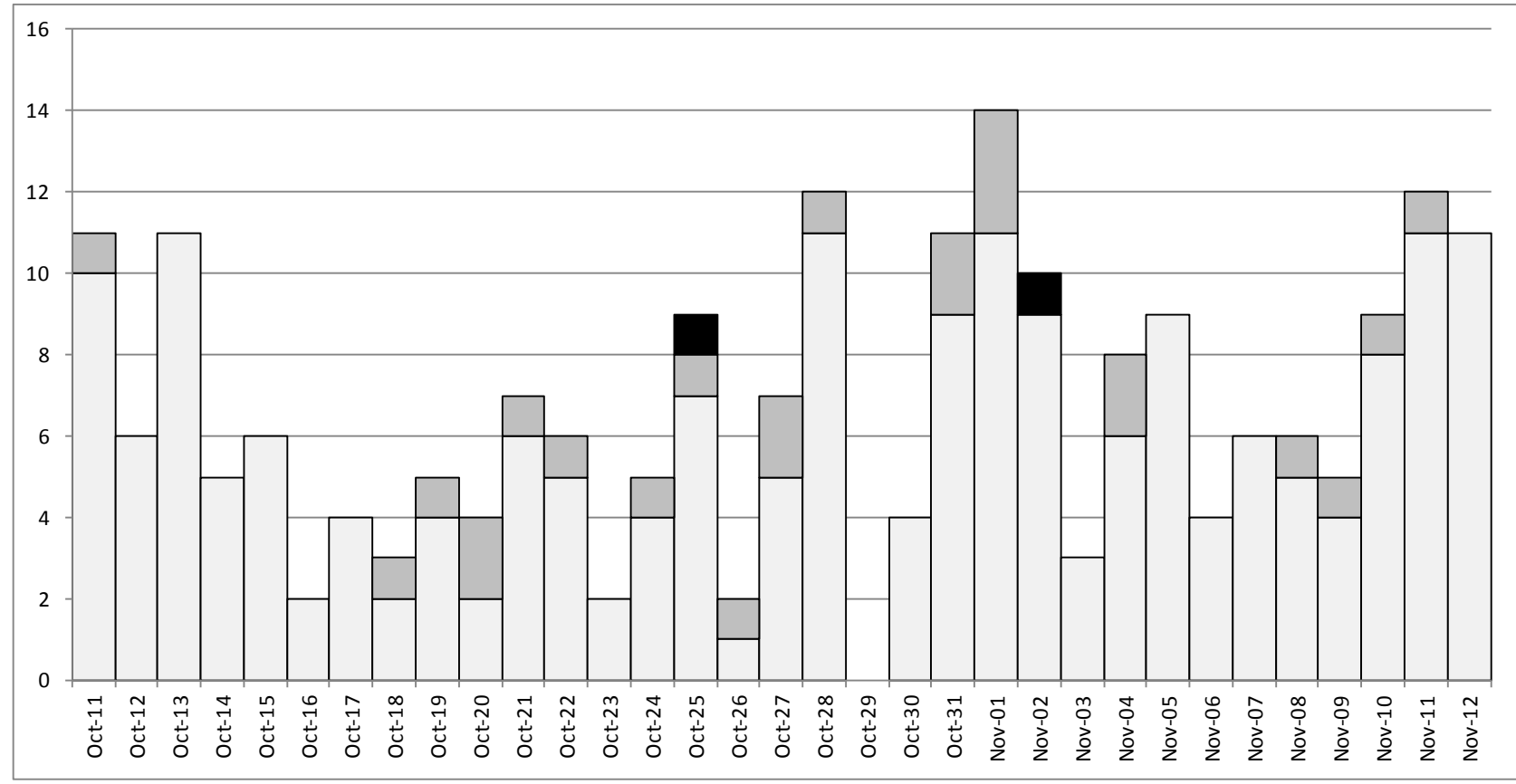

Figure 2. Aberrations Detected by Prescription Surveillance. Note: The lowest toned bar shows the number of low aberrations. The second toned bar shows moderate aberrations. The black bar shows high aberration. High aberrations found on 25 October and 2 November were detected for neuraminidase inhibitors. 


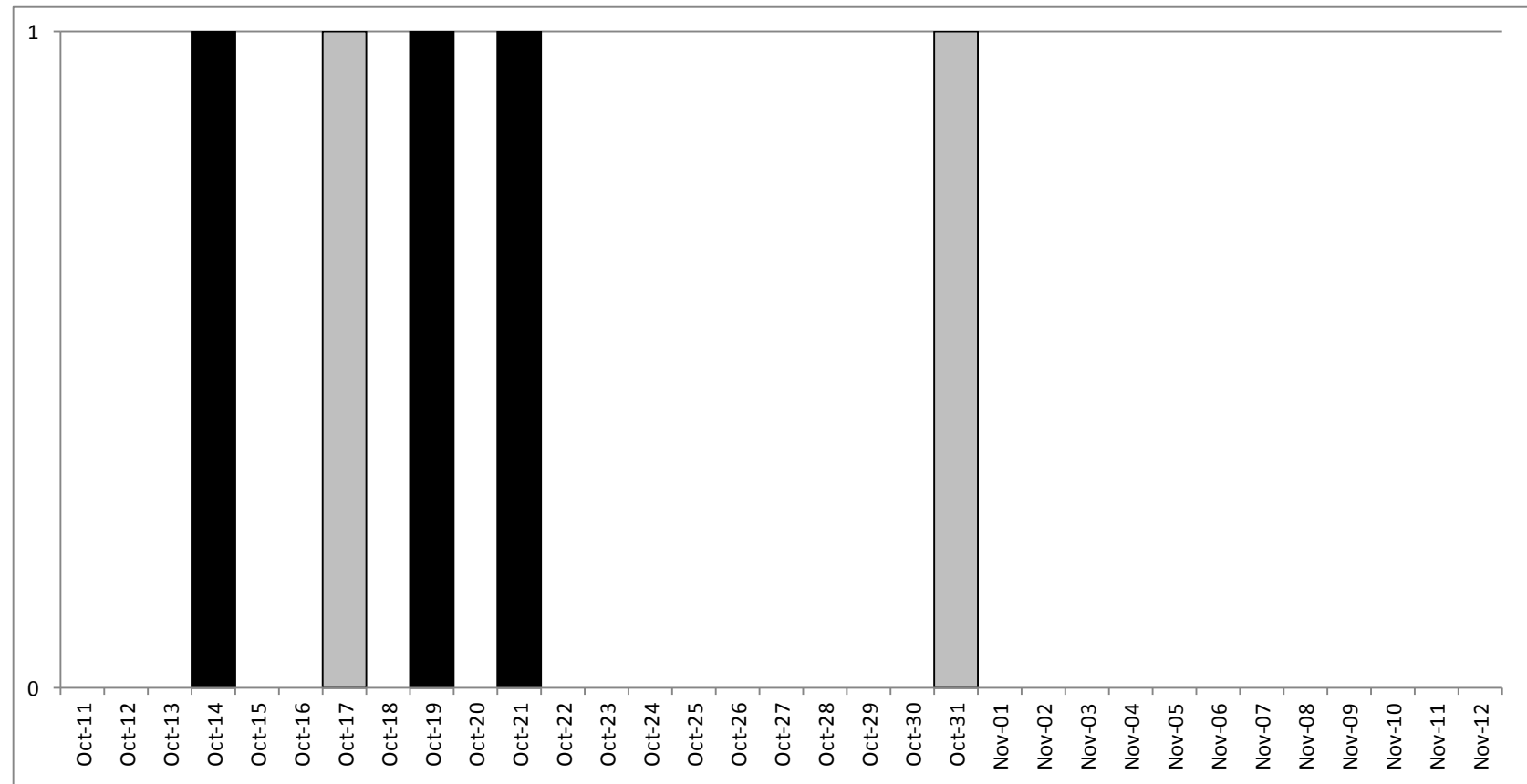

Figure 3. Aberrations Detected by Official Syndromic Surveillance and Notification of Measles in Okinawa. Note: Gray bars show the number of Official Syndromic Surveillance reported. Black bars show notification of measles in Okinawa reported. All Official Syndromic Surveillance reported cases met the second criterion.

center quickly. Results show that (N)SASSy is useful for diseases that require a public health response even if only one case is suspected, such as measles or rubella.

\section{Conclusions}

We conducted enhanced surveillance throughout Okinawa prefecture for 33 days from 12 October through 13 November, 2016, related with the Sixth Worldwide Uchinanchu Festival held during 26 - 30 October, 2016. We recognized again the importance of (N)SASSy, PS, and OSS to analyze and evaluate the official routine surveillance, and its importance for active surveillance or information collection if necessary.

On the other hand, we were unable to use the information of the ambulance transfer in this enhanced surveillance, which was sometimes used in past enhanced surveillance. It remains as a challenge for future study.

Our experience with this enhanced surveillance would be expected to be important lesson for countermeasures in Okinawa prefecture to increased risks of the infectious diseases due to the mass gathering events such as the routine Worldwide Uchinanchu Festival and import infectious diseases related to increasing numbers of foreign visitors and U.S. military bases.

\section{Acknowledgements}

We acknowledge all participants of the enhanced surveillance including (nursery) schools and pharmacies. We also acknowledge the Japan Medical Associa- 
tion, the Japan Pharmaceutical Association, School of Pharmacy, Nihon University and EM System Co. Ltd. as operator for PS and the Japanese Society of School Health as operator for (N)SASSy.

\section{References}

[1] WHO, WHO Director-General Summarizes the Outcome of the Emergency Committee regarding Clusters of Microcephaly and Guillain-Barré Syndrome. 2016.

http://www.who.int/mediacentre/news/statements/2016/emergency-committee-zika -microcephaly/en/

[2] Song, B.H., Yun, S.I., Woolley, M. and Lee, Y.M. (2017) Zika Virus: History, Epidemiology, Transmission, and Clinical Presentation. Journal of Neuroimmunology, 308, 50-64.

[3] Dafni, U.G., Tsiodras, S., Panagiotakos, D., et al. (2004) Algorithm for Statistical Detection of Peaks-Syndromic Surveillance System for the Athens 2004 Olympic Games. Morbidity and Mortality Weekly Report, 53, 86-94.

[4] Jorm, L.R., Thackway, S.V., Churches, T.R., et al. (2003) Watching the Games: Public Health Surveillance for the Sydney 2000 Olympic Games. Journal of Epidemiology and Community Health, 57, 102-108. https://doi.org/10.1136/jech.57.2.102

[5] Severi, E., Heinsbroek, E., Watson, C., et al. (2012) Infectious Disease Surveillance for the London 2012 Olympic and Paralympic Games. Eurosurveillance, 17, pii: 20232 .

[6] Osaka, K., Takahashi, H. and Ohyama, T. (2002) Testing a Symptom-Based Surveillance System at High-Profile Gatherings as a Preparatory Measure for Bioterrorism. Epidemiology \& Infection, 129, 429-434. (In Japanese) https://doi.org/10.1017/S0950268802007689

[7] Matsui, T., Takahashi, H., Ohyama, T., et al. (2002) An Evaluation of Syndromic Surveillance for the G8 Summit in Miyazaki and Fukuoka, 2000. Kansenshogaku Zasshi, 76, 161-166. (In Japanese) https://doi.org/10.11150/kansenshogakuzasshi1970.76.161

[8] Suzuki, S., Ohyama, T., Taniguchi, K., et al. (2003) Syndromic Surveillance of Infectious Diseases during the World Cup Football Games Held in Korea and Japan, May-July 2002. Infectious Agents Surveillance Report, 24, 37-38. (In Japanese)

[9] Kamiya, N., Ikeda, K., Nadaoka, Y., et al. (2002) The Syndrome Surveillance during FIFA 2002 World Cup TM. Annual Report of the Tokyo Metropolitan Research Laboratory of Public Health, 53, 287-292. (In Japanese)

[10] Ohkusa, Y., Yamaguchi, R., Sugiura, H., et al. (2009) 2008 G8 Hokkaido Toyako Summit Meeting Syndrome Surveillance. Kansenshogaku Zasshi, 83, 236-244. (In Japanese) https://doi.org/10.11150/kansenshogakuzasshi.83.236

[11] Ohkusa, Y., Sugawara, T., Masuda, K., et al. (2010) Enhanced Surveillance for US Presidential Visit to Japan. Kansenshogaku Zasshi, 84, 708-713. (In Japanese) https://doi.org/10.11150/kansenshogakuzasshi.84.708

[12] Inaba, S., Ohkusa, Y., Sugawara, T., et al. (2012) Operation and Evaluation of Enhanced Surveillance for COP10 at Nagoya in 2010. Japanese Journal of Disaster Medicine, 17, 326-333. (In Japanese)

[13] Sugishita, Y., Ohkusa, Y., Sugawara, T., et al. (2013) Enhanced Syndromic Surveillance for the Fourth Japan-China-South Korea Trilateral Summit 2011. Journal of Bioterrorism and Biodefense, 4, 1. https://doi.org/10.4172/2157-2526.1000126 
[14] Shimatani, N., Sugishita, Y., Sugawara, T., et al. (2015) Enhanced Surveillance for Sports Festival in Tokyo 2013: Preparation for Tokyo 2020 Olympic and Paralympic Games. Japanese Journal of Infectious Diseases, 68, 288-295. https://doi.org/10.7883/yoken.JJID.2014.233

[15] Hutwagner, L., Thompson, W., Seeman, G.M., et al. (2003) The Bioterrorism Preparedness and Response Early Aberration Reporting System (EARS). Journal of Urban Health: Bulletin of the New York Academy of Medicine, 80, i89-i96.

[16] Olson, D.R., Heffernan, R.T., Paladini, M., Konty, K., Weiss, D. and Mostashari, F. (2007) Monitoring the Impact of Influenza by Age: Emergency Department Fever and Respiratory Complaint Surveillance in New York City. PLOS Medicine, 4, e247. https://doi.org/10.1371/journal.pmed.0040247

Submit or recommend next manuscript to SCIRP and we will provide best service for you:

Accepting pre-submission inquiries through Email, Facebook, LinkedIn, Twitter, etc. A wide selection of journals (inclusive of 9 subjects, more than 200 journals) Providing 24-hour high-quality service User-friendly online submission system Fair and swift peer-review system Efficient typesetting and proofreading procedure Display of the result of downloads and visits, as well as the number of cited articles Maximum dissemination of your research work

Submit your manuscript at: http://papersubmission.scirp.org/

Or contact jbm@scirp.org 